\title{
Managing DANGerous GoOdS Risks ON ROADS DURING TRANSPORTATION UNDER NORMAL CONDITIONS
}

\author{
JANNO, J. \& KOPPEL, O.
}

Abstract: Transportation chain with regards to any mode of transport is a complex system with plenty of parties which assemble the variety of know-how on a different level of competence. In dangerous goods transport on roads, various aspects have to be considered in order to ensure safe transportation of dangerous goods. From the point of learning on different levels of a process, it is critical to define and handle these risks already at a primary level i.e. within a regular transportation chain under normal transportation conditions. The research studies links between general risks of the transport process and specific risks within the transportation chain of dangerous goods on roads. The paper presents a qualitative multiple case study research based on studies on operational risks with dangerous goods on roads as well as the analysis of procedures and actions of different parties involved within the transportation chain on an example of Estonia. As a result, essential risks of transportation process are identified upon internal risk types no matter what kind of specific characteristic the good has. Identifying overlapping risks can be further used as an essential input on how to estimate their proportions and possible value damage in road transportation.

Key words: dangerous goods transport on roads; risk management; overlapping risks; multiple case study research.
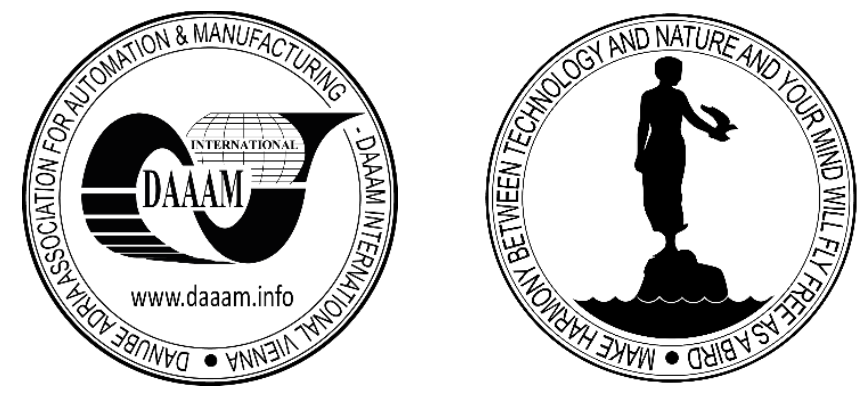

Authors' data: MSc. (Eng.) Janno, J[elizaveta]; Univ. Prof. Ph.D. Koppel, O[tt], Tallinn University of Technology, Ehitajate Street 5, 19086, Tallinn, Estonia, jelizaveta@tktk.ee,ott.koppel@ttu.ee

This Publication has to be referred as: Janno, J[elizaveta] \& Koppel, O[tt] (2017). Managing Dangerous Goods Risks on Roads during Transportation under Normal Conditions, Chapter 25 in DAAAM International Scientific Book 2017, pp.333-344, B. Katalinic (Ed.), Published by DAAAM International, ISBN 978-3-902734-12-9, ISSN 1726-9687, Vienna, Austria

DOI: $10.2507 /$ daaam.scibook.2017.25 
Janno, J. \& Koppel, O.: Managing Dangerous Goods Risks on Roads during Transp...

\section{Introduction}

The essential role of transport is to facilitate the movement of goods. Operations within a transportation chain are vulnerable to many types of risks due to an increasing dynamics and structural complexity of today's supply chain networks. Global distributed sourcing and production lead to more transported goods in general but also to more high-value cargoes being shipped around the world (Skrona et al. 2011).

Supply chains in globalized markets consist of a number of interconnected and independent companies. Hence, the key to connectivity is in the transportation chains. It is necessary to continuously control and manage the potential risks that could disrupt the transport chain, and consequently result in a disruption in the supply chain. There are various models of risk assessment and its management, and the choice depends on various factors that may have an impact on the functioning of the transport system. There is also no unique solution for decision-making related to risks for each transportation chain, as it depends on various factors, such as the number of links, phases of the supply chain which it connects, distance etc. (Stažnik et al., 2017).

Because of the increasing dynamics and complexity of the structure of nowadays transport networks, transportation chains are susceptible to many types of risks. (Ibid.). The aim of this paper is to identify basic risks within the transportation chain under normal conditions and on this basis to define breakpoints that are critical when managing risks within a dangerous goods transportation chain. This paper aims to contribute to reducing the problem of risk management of dangerous goods transportation by roads by presenting a model of overlapping risks areas regardless of the characteristics of the goods. The goals of the paper are following:

- to identify risks groups with similar characteristics between transportation chains under normal and specific (in this case dangerous goods transport) conditions;

- to test the model and to create an integrated view of overlapping risks between operations of different types of transportation chains to highlight the core issue that would further lead to possibilities to manage dangerous goods risks on roads during transportation under normal conditions.

Based on previous studies on general identification and analysis of risks in transportation chains as well as on specific studies on operational risks within dangerous goods transportation chain, a preliminary perspective of risks groups with similar characteristics between regular and dangerous goods transportation chain is framed. With regards to this study, regular transportation chain is defined as a set of simple transportation-related procedures due to conventional good. Next, accordingly, to results of multiple case study research, a comprehensive framework with overlapping risks is developed. Results have a significant importance for all parties within a transportation chain (consignors/ consignees; freight forwarders; transportation companies, and drivers) as they draw attention to critical aspects to manage risks in regular transportation chain and therefore reduce them when transporting dangerous goods by roads. In the scope of further studies, it is relevant to continue risk analysis by calculating costs of risks (financial, economic) and focus on detailed research of particular risk management tools in the scope of overlapping risks 
by members of transportation chain separately in order to maximize the level of safety in dangerous goods transportation.

\section{Literature review}

As supply chains evolve into collaboration networks with a more complicated pattern, the complexity of transportation chains grows with this hand in hand. This leads to a fact that transportation process with its parties and operations involved is open to many types of risks. The identification of risks and risk management in transportation chain has been studied from the different perspective and results can be found in various literature, and in accordance with the topic studied the risk management related to the transport system in general.

Within the research on the multimodal maritime supply chain in the Gulf of Finland area, the process and the structure of a new framework for categorizing risks in terms of their driver factors were mapped (Vilko \& Hallikas, 2012). Specific risks associated with the supply chain were identified within a supply chain process by operational environment, actors, and process phases within. In following analysis risks and their effects were identified upon the likelihood and the effect info following categories: supply risks, operational risks, security risks, macro risks, policy risks, and environmental risks. As a result, detailed identification of risks shows the higher-level steps in the process and allows in-depth focusing on each stage without losing the connections between these stages.

In some studies on dangerous goods specifically, Bayesian networks have been implemented to prioritize the factors that influence dangerous goods (according to Hazmat hazardous materials) transportation accidents (Zhao et al., 2012). The Bayesian network structure was built based on expert knowledge using DempsterShafer evidence theory, and the structure was modified based on a test for conditional independence. On a basis of 94 cases of Chinese, Hazmat transportation accidents were analysed to compute the posterior probability of each factor using the expectationmaximization learning algorithm. It was found that three most influential factors in Hazmat transportation accidents were human factors, the transport vehicle and facilities, and packing and loading of the Hazmat. These findings provide an empirically supported theoretical basis for Hazmat transportation corporations to take corrective and preventative measures to reduce the risk of accidents.

According to the qualitative studies of managing risks in dangerous goods transportation (Krasjukova, 2012), three main decision criteria were identified in the sphere of DG road transportation. These can be accepted as assets of preventive means derived out of technical, procedural or staff factors. Moreover, this position was used as a basis for the identification and the evaluation of operational risks within the dangerous goods transportation chain in Estonia (Janno \& Koppel, 2017, a). According to results of risk identification and evaluation by members of a dangerous goods transportation chain separately, it is underlined that operational risks influence participants' activity differently within a dangerous goods transportation chain. Consignor's/ consignee's and carrier's risks were considered as most severe when handling and transporting dangerous goods by roads. 
Dangerous goods transportation by roads contains more risks than a regular transportation chain. This is caused due to a greater number of parties involved in the whole process, due to additional procedures and due to special characteristics of a good. In the scope of this paper is to focus on overlapping risks of regular and dangerous goods transportation chain and to identify links how to prevent dangerous goods risks during transportation under normal conditions i.e. in the regular transportation chain. In following parts, the comparability analysis and qualitative multiple case study research are applied to define overlapping risks through practical standpoint. The limited number of case studies selected into the research is caused due to the data protection issues in Estonia. Despite this, the sample was formed adequately and is relevant from the point of research problem on the example on Estonia.

\section{Background}

The problem of risk management is a global problem that requires global solutions (Stažnik et al., 2017). Systemic risks within a supply chain and transport networks are common and are characterized by an unexpected trigger event and a network setup that cannot absorb the shock and knock-on effects. However, prediction of specific disruptions that can result from failures across regions or industries is felt to be less important than having the resiliency in place for effective response, no matter what is the cause (World Economic Forum, 2012). Identified vulnerabilities of most concern that limit the resilience of supply chain and transport networks are hereby illustrated in a following Fig. 1. Based on a comprehensive understanding of external disrupters and network vulnerabilities, the latter mentioned can magnify the impact of disruption.

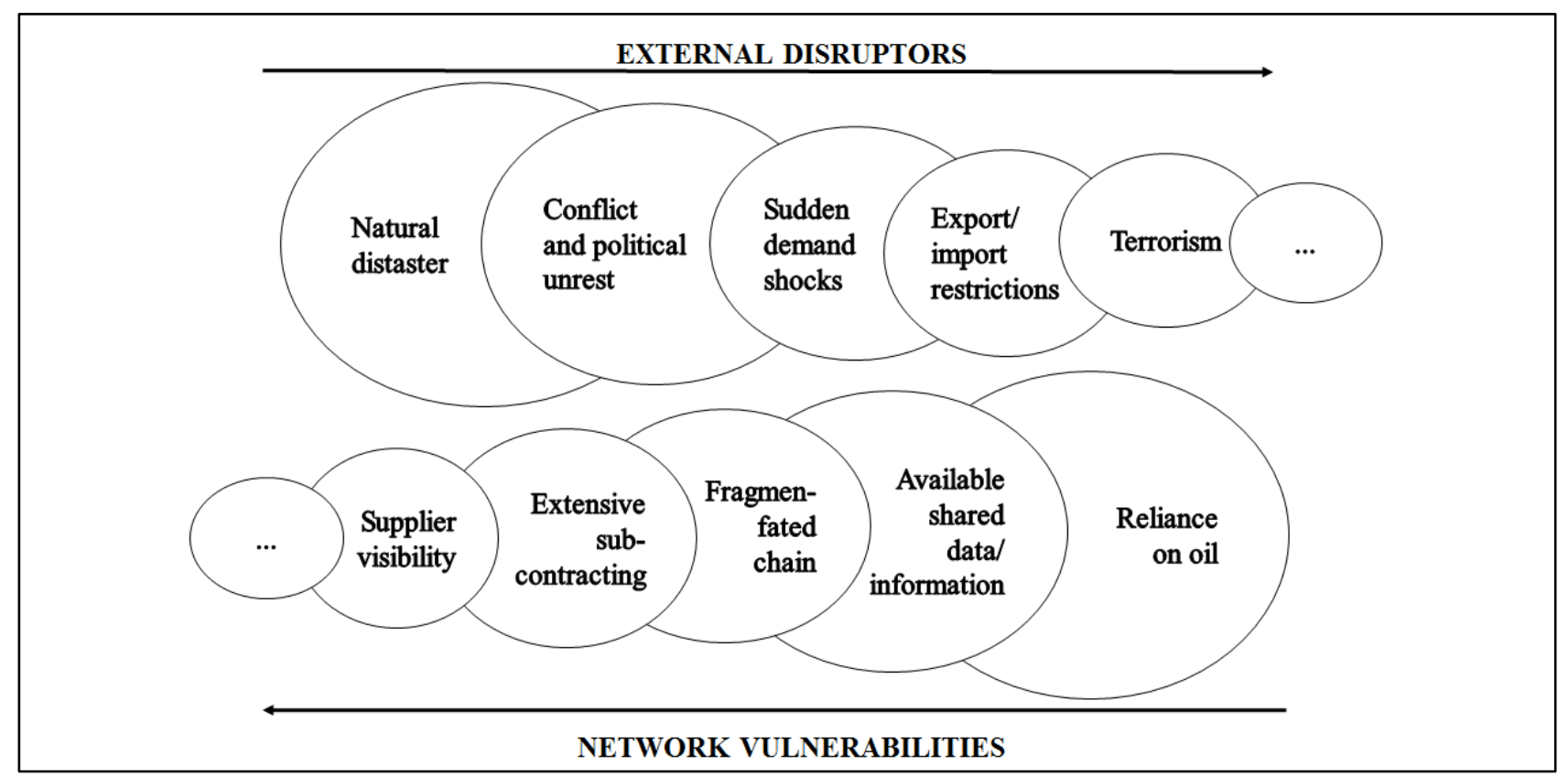

Fig. 1. Risk exposure in transportation chain.

External disasters lead directly to network vulnerability issues that influence overall risk management of a transportation chain. According to several empirical studies (Boone, 2000; Forigua \& Lyons, 2015; Stažnik et al., 2017; World Economic 
Forum, 2012) the most commonly used classification between different types of internal risks within a regular transportation chain can be summed up as follows:

- physical risk - thefts, losses;

- operational risk - damage through rough handling, delivery failure, customs clearance;

- employee risk - transport accidents, collisions;

- risks related to technology in use - technical issues.

When identifying risks of a transportation chain with specific characteristics (in this case dangerous goods transportation chain), it is important to pay attention both on external as well as on internal risks of a system. The internal risk may result from several factors; some of them are internal while others are external. The internal factors appear from the inside of a system and they can be approximately controlled (Mohammad et al., 2014). External risks are on the other hand appeared from outside the organization but they cannot be controlled as the internal factors (Ibid). Identifying and assessing likely risks and their possible impact on operations is a complex and difficult task for a single company. Operational risk can be summarized as a human risk; it is the risk of business operations failing due to human error. Industries with lower human interaction are likely to have a lower operational risk (Investopedia, 2017). However, to properly assess vulnerabilities in a supply chain, firms must not only identify direct risks to their operations but also the risks to all other entities as well as those risks caused by the transportation linkages between organizations (Jüttner, 2005). Based on research on operational risks in transportation chain of dangerous goods in Estonia upon its parties separately (Janno \& Koppel, 2017) risks related to documentation issues and inaccurate customer communication were identified as highest as shown in the following Fig. 2.

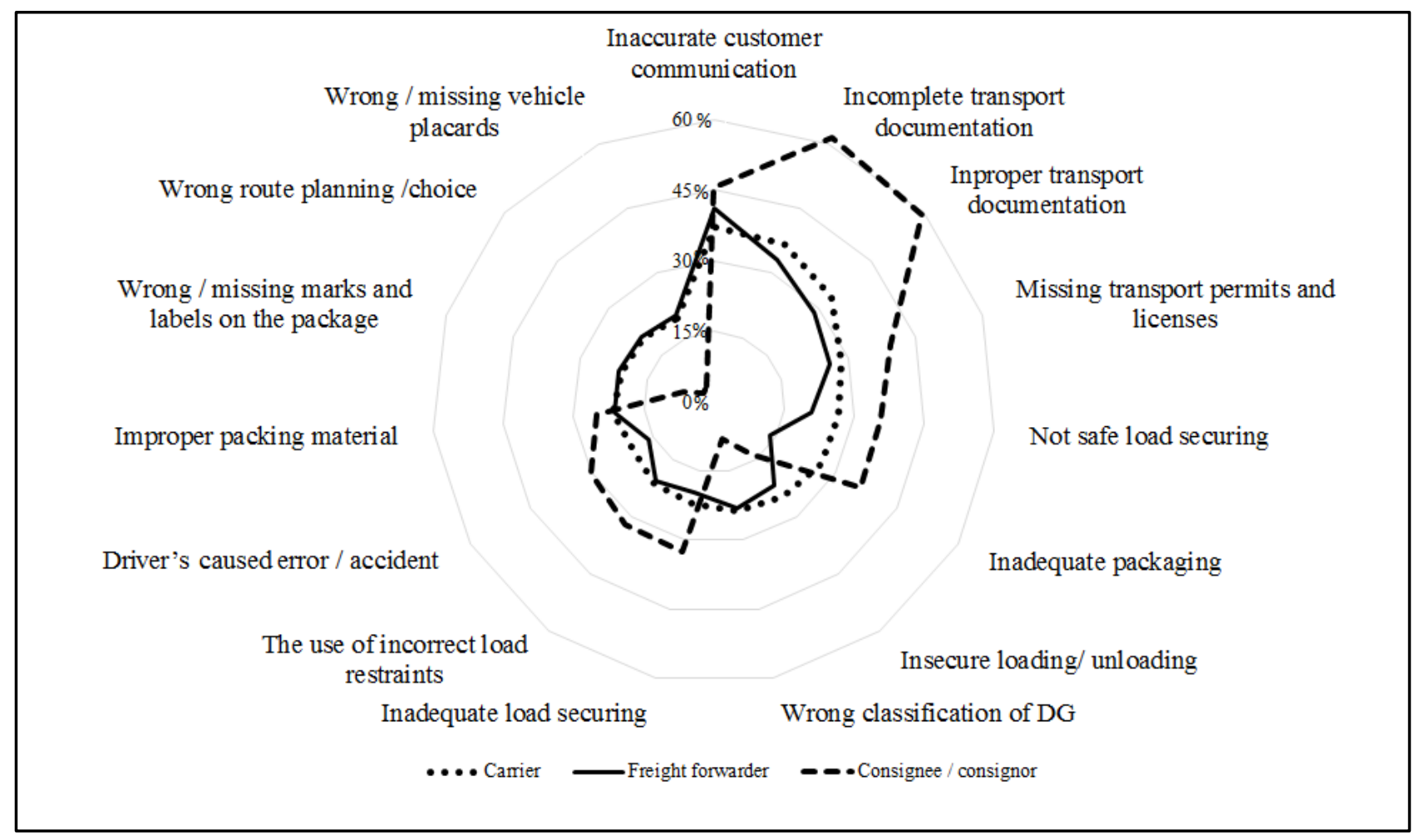

Fig. 2. Operational risks in dangerous goods transportation chain. 
Risk management is not a one-time process (Kremljak, 2016). Risks should always be identified at the beginning of the project during the up-front planning process, as well as they should also be periodically looked at remaining work to identify any new risks. Risk management related to the transportation and logistics chain includes processes which reduce the probability of occurrence and/ or impact that detrimental supply chain events have on the specific company (Zsidisin and Ellram, 2003). Risks in a transportation chain have a different nature. In the scope of this paper, the research focuses on how to manage internal risks (in this case, operational risks) of a dangerous goods transportation within a transportation process of normal conditions in regular transportation chain.

\section{Methodology}

\subsection{Problem description}

Customers in today's complex supply chain systems, demand high levels of flexibility and customization, information systems integration, and fast transit times, but all at low costs. Therefore, transportation networks are highly complex and tightly-coupled systems that are vulnerable to many types of disruptions (Skrona et al., 2011). In the presence of complexity and tight-coupling, supply chain systems become prone to accidents (Wagner \& Bode, 2007). In order to impose a proactive risk management system, it is essential to have reliable preconditions on the major pain points in transportation within a regular transportation process that in advance mitigate risks when transporting dangerous goods. This matter has not received so far significant attention, as management of dangerous goods is rather short-sighted action within the process than proactive operating beyond standard procedures within a transportation chain.

The goal is not to predict what or when is going to happen, but instead be prepared and able to respond in an informed and planned manner to minimize the impact of a disruption (World Economic Forum, 2012). Regardless of the mode of transport dangerous goods transportation can be considered as an advanced level of a regular transportation chain. Additional complexity is caused due to extra requirements on personnel qualification as well as on procedures within dangerous goods transportation chain. The risk management of a dangerous goods transportation chain with regards to operational risks should start at a higher level of a transportation network.

To characterize a problem from a practical point of view, the dangerous goods related training system in Estonia is a substantial issue at this point. At the moment professional driver training in Estonia doesn't include theoretical preparation related to dangerous goods as there are specific initial and refresher dangerous goods training (ADR training that is regulated by The European Agreement concerning the International Carriage of Dangerous Goods by Road) for drivers. Due to specific dangerous goods transportation regulations on road, there are specific conditions when it is possible to transport dangerous goods on simplified clauses and in this case, a driver doesn't need to have a training certificate (according to ADR regulations). There is a clear contradiction in a fact that professional driver training doesn't prepare drivers to manage risks when transporting chemicals under simplified conditions. In order to 
foresee similar gaps as early as possible within this paper overlapping risks of transportation chains with different features are studied on a basis of practical cases of parties involved in dangerous goods transportation chain.

\subsection{Research design}

This paper follows the steps of a qualitative research design that is defined by a research problem according to which risk management in dangerous goods transportation chain is short-sighted and is focused rather on the elimination of consequences than on ensuring safety proactively. As the research design refers to the logical structure of the study (Yin, 2009), in the scope of this paper qualitative data collection and analysis methods were selected to present relevant results how to reduce the problem of risk management of dangerous goods transportation on roads. As a result, a model of overlapping risks areas regardless of the characteristics of the goods is presented.

Within the process of developing a research, the study is spread into multiple distinct stages upon how the data is collected and how it has been analysed. In order to implement comparability analysis in the first stage of a research, previous studies on a topic related to risks in transportation chain on roads are studied in advance. Based on a theory of the comparability analysis is a comparison of a controlled transaction with an uncontrolled transaction (or transactions). A comparable uncontrolled transaction is a transaction between two independent parties that is comparable to the controlled transaction under examination. It can be either a comparable transaction between one party to the controlled transaction and an independent party (internal comparable) or between two independent enterprises, neither of which is a party to the controlled transaction (external comparable) (OECD, 2010). In the scope of this study risks between two transportation chains are in focus - regular and dangerous goods transportation chain that represent two independent parties and are comparable externally.

In the second stage of a research, the multiple case study research is implemented as the main method to analyse practical cases on dangerous goods transportation by roads on the example of Estonia's companies. The multiple case study design can be adopted with real-life events that show numerous sources of evidence through replication rather than sampling logic. Generalisation of results from case studies, from either single or multiple designs, stems on theory rather than on populations (Yin, 2009). By replicating the case through pattern-matching, a technique linking several pieces of information from the same case to some theoretical proposition (Campbell, 1975), multiple case design enhances and supports the previous results. From the perspective of this study, this helps raise the level of confidence in the robustness of current method as well as validates preliminary results from the first stage of the research. As a result, a comprehensive framework with overlapping risks is developed.

The following chapter gives an overview of results of qualitative analysis of transportation chains at two stages of the study. At first, the comparability analysis is implemented in order to identify overlapping risks within regular and dangerous goods transportation chains. Therefore, secondary data in form of results of previous studies on risks management in transportation is used. In the second stage of a study, four practical case studies as preliminary data on dangerous goods transportation process 
are presented with the aim to find support points for possibilities to manage dangerous goods risks during transportation under normal conditions, i.e. in regular transportation chain.

\section{Results}

\subsection{Comparability analysis}

When framing the preliminary perspective of the similar type of risks between regular and dangerous goods transportation chain, internal risks of a transport system were studied on different levels. By implementing comparability analysis method and moving from outside (I level) to inside (II level) internal risks of a transportation chain (system) were systematically linked to specific operational risks of dangerous goods transportation chain. The initial perspective of risks groups with similar characteristics of regular and dangerous goods transportation chain is framed and presented in following Fig. 3.

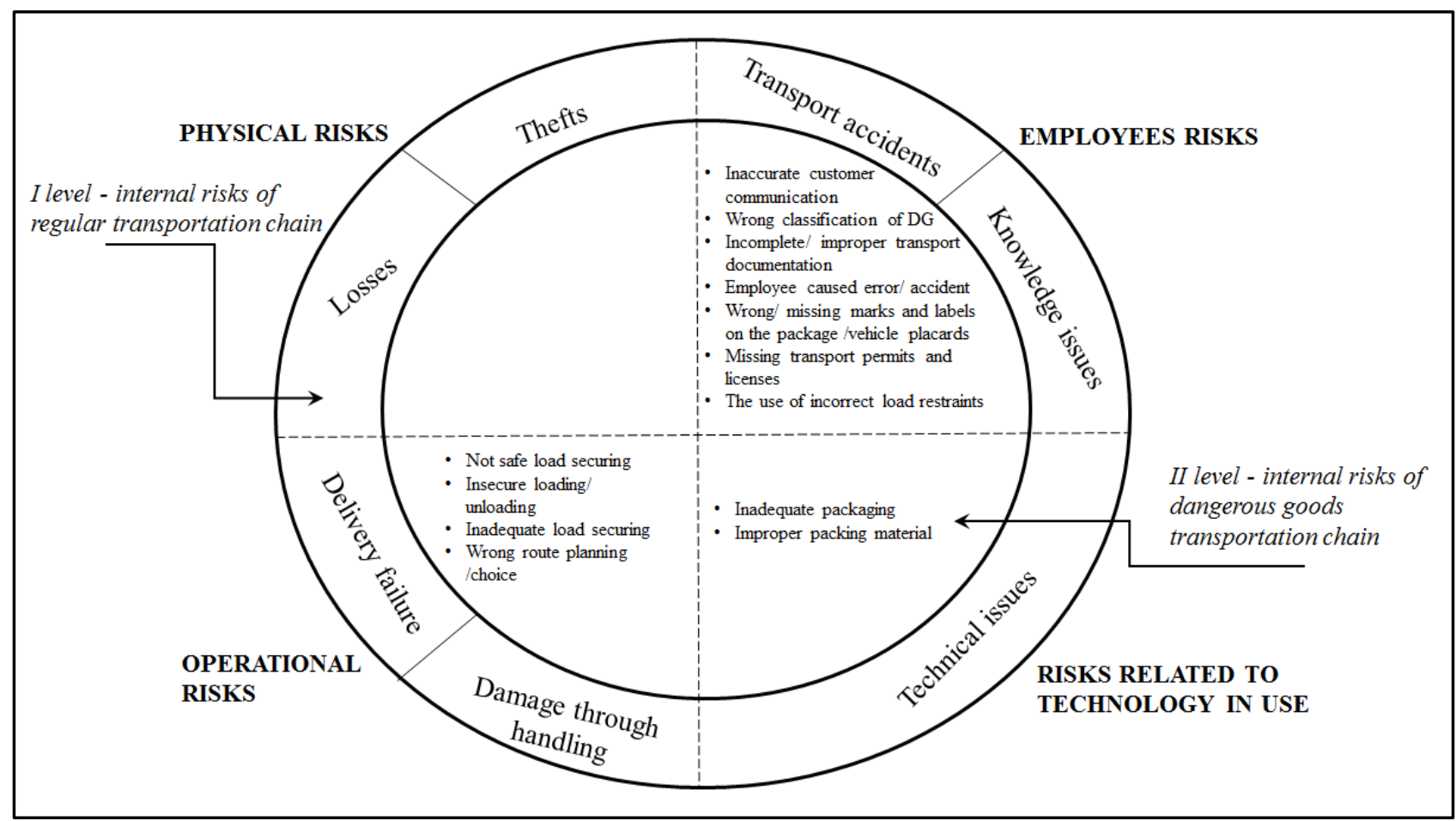

Fig. 3. Internal risk model of a multi-level transportation chain.

Results of a comparability analysis refer to a clear dominance of dangerous goods risks that are on a more general internal risk classification level related to operations and employees. In the scope of conditional comparison at the first stage of a study, there are no such risks within a dangerous goods transportation chain that indicate to direct physical risks such as theft or a loss of a cargo.

In the following stage of a research, multiple case study analysis is implemented in order to validate and structure initial risks logically and to identify straightforward relations in the scope of overlapping risks. 


\subsection{Multiple case study research}

The selection of dangerous good specific case studies into the second part of a study was performed purposefully as an aspect of a data protection turned out to be a critical constraint. Designed sampling is qualified as purposive sampling where subjects are chosen to be part of the sample with a specific purpose in mind that is sufficient to draw objective conclusions concerning the methodological approach of some subjects that fit for the research compared to other individuals (Babbie, 2010).

\begin{tabular}{|c|c|c|}
\hline $\begin{array}{l}\text { Case } \\
\text { No. } \\
\end{array}$ & Remarks on case studies & $\begin{array}{l}\text { Logical linking of } \\
\text { internal risks }\end{array}$ \\
\hline Case 1 & $\begin{array}{l}\text { - Unloading of a 20' tank-container at consignee } \\
\text { into a stationary non-portable tank; } \\
\text { - unloading procedure was carried out in a way } \\
\text { that the tank-container is under pressure and } \\
\text { the good is pressed out into the stationary tank; } \\
\text { - the stationary tank was pumped over and } \\
\text { spillage occurred. }\end{array}$ & $\begin{array}{l}\text { OPERATIONAL } \\
\text { RISK } \rightarrow \text { damage } \\
\text { through handling } \rightarrow \\
\text { insecure loading/ } \\
\text { unloading }\end{array}$ \\
\hline Case 2 & $\begin{array}{l}\text { Transporting full trailer load of IBCs that are } \\
\text { less than } 90 \% \text { loaded with liquid chemicals; } \\
\text { - additional slopping of a transportation unit in } \\
\text { the traffic due to the redundant clucking of a } \\
\text { liquid within a transportation package; } \\
\text { - in order to prevent evident accident reducing } \\
\text { speed in traffic to ensure safety, delay for } \\
\text { unloading at consignee. }\end{array}$ & $\begin{array}{l}\text { EMPLOYEES RISK } \\
\rightarrow \text { knowledge issues } \\
\rightarrow \text { employee caused } \\
\text { error/ accident }\end{array}$ \\
\hline Case 3 & $\begin{array}{l}\text { - Dangerous goods shipment within a groupage } \\
\text { shipment; } \\
\text { - another shipment was loaded on ADR } \\
\text { shipment and caused the spillage of a } \\
\text { dangerous good within a transportation unit. }\end{array}$ & $\begin{array}{l}\text { EMPLOYEES RISK } \\
\rightarrow \text { knowledge issues } \\
\rightarrow \text { employee caused } \\
\text { error/ accident }\end{array}$ \\
\hline Case 4 & $\begin{array}{l}\text { A tank truck drove off the road and fell } \\
\text { sideways; } \\
\text { - nearest households in a } 200 \text {-meter radius; } \\
\text { - people evacuated within an } 800 \text {-meter radius; } \\
\text { - a high risk of cargo to expand as it started to } \\
\text { warm up in a vehicle tank, this could lead to an } \\
\text { explosion; } \\
\text { - no possibilities to let the substance out of the } \\
\text { tank, no appropriate means of pumping; } \\
\text { - tank truck was pulled out of the ditch without } \\
\text { leakage nor additional danger, nearby } \\
\text { inhabitants returned to their residences. }\end{array}$ & $\begin{array}{l}\text { EMPLOYEES RISK } \\
\rightarrow \text { transport } \\
\text { accidents } \rightarrow \\
\text { employee caused } \\
\text { error/ accident }\end{array}$ \\
\hline
\end{tabular}

Tab. 1. Formation of logical linking of overlapping risks. 
The Table 1 presented above gives a comprehensive overview of relevant criteria of selected cases on dangerous goods transportation by roads and represents a logical linking of internal risks among different types of transportation chain. In cases presented above, types of particular dangerous goods have not been mentioned on purpose, as additional risks due to chemical characteristics of a good are not in focus as they are not related to internal risks of a transportation chain. Altogether, the data on four carefully selected cases were collected from different parties of dangerous goods transportation chain of Estonia.

By implementing multiple case study research methodology, selected cases have been studied with the use of internal risk model of a multi-level transportation chain. When analysing each case step-by-step using this model it is possible to create connections between procedures of regular and dangerous goods transportation chain. This allows creating an integrated view of overlapping risks of operations of different types of transportation chains to highlight the possibilities to manage dangerous goods risks on roads during transportation under normal conditions.

The results highlight the possibility to bind risks of transportation chains with different types of cargo as well as with different procedural characteristics. According to results from Table 1, insecure unloading procedure in a dangerous goods transportation chain, (as it is described in Case 1, that ended up with spillage of chemicals), is related to the risk of damage through handling in a regular transportation chain (i.e. under normal conditions). These combinations of related risks through over transportation chains with different characteristics are overlapping risks. By knowing these overlapping risks with their possible consequences in a regular transportation chain, it is possible to manage them proactively in advance with regards to dangerous goods transportation chain.

Due to the high risk of dangerous goods, there is a must to learn before doing in the content of ensuring safety (Janno \& Koppel, 2017, b). Empirical results in form of multiple-case study analysis don't allow to make conclusions on prioritization of overlapping risks of internal risks of regular and dangerous goods transportation chain. This is justified due to a small number of case studies involved in the study. However, the fact of possibility to link internal risks of transportation chains with different characteristics found the proof. Developed internal risk model of a multi-level transportation chain is an important tool in the scope of working on further research directions with the focus to estimate proportions and possible value damage of risks in road transportation.

\section{Conclusion}

There are many prescriptions, which need to be followed by different parties within the transportation chain of dangerous goods in order to ensure safe transportation and handling operations as well as to minimize operational risks related to human factor (Janno \& Koppel, 2017, b). In order to reduce and manage risks effectively throughout the whole supply chain as well as the transportation network, a proactive risk management concepts have to be implemented. In scope of present paper, detailed comparability analysis of risks in transportation chains with different 
features were performed and internal risk model of a multi-level transportation chain was developed. It was then implemented in the second phase of a research in parallel with multiple case study analysis. At this phase of a research previously developed, preliminary internal risk model was validated. When analysing case studies and trying to identify the core issue, the principle of an internal risk model was used and compatibility between internal risks of a transportation chain on a regular basis and operational risks of a dangerous good chain was identified.

On a national scale, it is shown that dangerous goods accidents on roads make up no more than $0.1 \%$ of total accidents in Estonia (Eurostat, 2016). But, even though this probability is minimal, the consequences are important when dangerous substances are involved. Findings, with regards to the identification of possibilities that focus on the internal risks within regular transportation chain, can mitigate the risks associated with dangerous goods, was confirmed, as overlapping risks were defined. In further studies, particular attention should be paid to operational risks and risks related directly to employees. The developed internal risk model of a multi-level transportation chain is of a universal nature mainly. Differences appear in the scope of specific operational risks of the dangerous goods transportation chain, which have to be identified individually on a national level.

\section{References}

Babbie, E. R. (2010). The practice of social research. Belmont: Wadsworth Publishing, ISBN 97804955984110495598410

Boone, J. (2000), Competitive pressure: the effects on investments in product and process Innovation, RAND Journal of Economics, Vol. 31(3), pp. 549-569, ISSN: 07416261

Campbell, D., (1975). Degrees of freedom and the case study. Comparative Political Studies, 8, pp. 178-185

Eurostat 2016. (2017). Energy, Transport and Environment Indicators Available from: $\mathrm{http}: / /$ ec.europa.eu/eurostat/documents/3217494/7731525/KS-DK-16-001-EN-

N.pdf/cc2b4de7-146c-4254-9521-dcbd6e6fafa6 Accessed on: 2017-09-29

Forigua, J., Lyons, L. (2015). Safety analysis of transportation chain for dangerous goods: A case study in Colombia, Proceedings of the 9th International Conference on City Logistics, Transportation Research Procedia Vol. 12, pp. 842 - 850. Tenerife, Spain. ISSN 2352-1465, Tenerife, Spain, June 2015, Elsevier B.V.

Janno, J., Koppel, O. (2017). Human factor as the main operational risk in dangerous goods transport chain. Proceedings of the 17th International Scientific Conference Business Logistics in Modern Management, Dujak, D. (Ed.), pp. 63-78. Osijek, Faculty of Economics in Osijek. ISBN 18495931, Osijek, Croatia, October 2017, Faculty of Economics in Osijek, Osijek

Janno, J., Koppel, O. (2017). Integrating interactive teaching methods into ADR training course system in Estonia. Proceedings of the 17th International MultiConference Reliability and Statistics in Transportation and Communication, Kabashkin, I.V., Yatskiv, I.V. (Ed.), Riga, Latvia, October 2017 (Unpublished) 
Janno, J. \& Koppel, O.: Managing Dangerous Goods Risks on Roads during Transp...

Investopedia. (2017). Operational Risk. Available from: $\mathrm{http}: / /$ www.investopedia.com/terms/o/operational_risk.asp\#ixzz4gWTRv0q8 Accessed on: 2017-10-01

Jüttner, U. (2005): Supply chain risk management: Understanding the business requirements from a practitioner perspective, in: International Journal of Logistics Management, Vol. 16 (1), pp. 120-141, ISSN: 0957-4093

Kremljak, Z[vonko] (2016). Risk Analysis of Specific Project Problems, Proceedings of the 27th DAAAM International Symposium, pp.0074-0081, B. Katalinic (Ed.), Published by DAAAM International, ISBN 978-3-902734-08-2, ISSN 1726-9679, Vienna, Austria

Krasjukova, J. (2012). Practical output of dangerous goods training on example of Estonia's carriers. NOFOMA 2012 - Proceedings of the 24th Annual Nordic Logistics Research Network Conference. NOFOMA 2012. 7-8 June 2012, Naantali, Finland. University of Turku. Turku University Press, pp. 471-486

Mohammad, A., Ghwanmeh, S., Alibrahim, A. (2014). Establishing Effective Guidelines to avoid Failure and Reducing Risk in E-Business. International Journal of Current Engineering and Technology, Vol. 4(1), (2014), pp. 28-31, E-ISSN 2277 4106

Organisation for Economic Co-Operation and Development. (2010). Comparability. OECD. July 2010. Centre for Tax Policy and Administration. Available from: http://www.oecd.org/tax/transfer-pricing/45765363.pdf Accessed on: 2017-10-07 Stažnik, A., Babić, D., Bajor, I. (2017). Identification and analysis of risks in transport chain. Journal of Applied Engineering Science. Vol. 15(1), (2017), pp. 61-70, ISSN $1451-4117$

Skrona, A. C. H., Bode, C., Weiss, M. (2011). Risk and loss prevention within the transport chain. Proceedings of 20th International Conference on Management of Technology, ISBN 978-0-9815817-4-3, Miami, Florida April 2011

Vilko, J.P.P., Hallikas J.M. (2012). Risk assessment in multimodal supply chains, International Journal of Production Economics, Vol. 140(2), (2012), pp. 586-595, ISSN 0925-5273

Zhao L., Wang X., Qian Y. (2012). Analysis of factors that influence hazardous material transportation accidents based on Bayesian networks: A case study in China. Safety Science, Vol. 50(4), (April 2012), pp.1049-1055, ISSN: 0925-7535

Wagner, S. M.; Bode, C. (2007). An empirical investigation into supply chain vulnerability, Journal of Purchasing and Supply Management, Vol. 12 (6), pp. 301312, ISSN: $1478-4092$

World Economic Forum. (2012). New Models for Addressing Supply Chain and Transport Risk. Available from: http://www3.weforum.org/docs/WEF_SCT_RRN_NewModelsAddressingSupplyCha inTransportRisk_IndustryAgenda_2012.pdf Accessed on: 2017-10-14

Yin, R. K. (2009). Case Study Research Design and Methods (4th ed.). Thousand Oaks, CA: Sage publications Inc. ISBN: 978-1-412-96099-1

Zsidisin, G. A., Ellram, L. (2003). An agency theory investigation of supply chain risk management, Journal of Supply Chain Management, Vol 39 (3), pp. 15-27, ISSN 1745493X 